\title{
International Schools for Young Astronomers, Astronomically Developing Countries, and Lonely Astronomers
}

\author{
By Donat G. Wentzel
}

Secretary for ISYA and TAD

Department of Astronomy, University of Maryland, College Park MD 20742, USA

wentzel@astro.umd.edu

\section{Goals}

Early in this century, many cities and universities could support telescopes large enough to do serious research. There were significant observatories even in the less accesable parts of the world. Astronomy was very much an international science, and the IAU was founded to aid this international outlook.

In the middle of this century, astronomy changed in two ways. First, the frontier research turned to new topics. It needed telescopes too expensive for most small and many large countries. Second, physics became a more prominent part of astronomy. That left many of the existing small observatories scientifically isolated, especially in developing countries. The scientifically lonely astronomers there needed new alliances to survive.

Simultaneously, the new prominence of physics led to astronomers appearing in physics departments of developing countries. These new astronomers were also isolated and they also needed to build alliances to survive.

Since the 1960s, the IAU has tried to support astronomy in developing countries, especially the lonely astronomers, by several teaching-related projects, supervised by IAU Commission 46. I shall tell you the more formal aspects of these projects, and then I want to summarize some of the successes and difficulties. But first I want to emphasize an important principle for each of these projects:

Any country or university where the IAU helps to develop astronomy must contribute significantly to this project. The more usual alternative has been tried by other scientific societies. Typically, they donated a piece of research equipment. Far too often several years later, the equipment has been found rusting in some corner. Those of you familiar with tropical countries know that rust destroys neglected equipment very rapidly. The projects of the IAU have minimized equipment and focused on the human contributions. We have selected countries and universities where we are reasonably assured of long term interest because these countries and universities are willing to contribute themselves.

\section{The International Schools for Young Astronomers (ISYA)}

There have been 22 ISYA: One each in UK, Italy, Greece, Spain, Portugal, Yugoslavia, Nigeria, Morocco, Malaysia, and Cuba; two each in India, Indonesia, China, Egypt, Argentina, and Brazil. The next ISYA will probably take place in Iran during July 1997.

The schools have evolved over the years. During the last dozen years, typically, the schools have been in Asia, Africa, and Latin America. They have been three weeks long. There have been four foreign faculty and one or more local faculty, teaching perhaps a dozen foreign participants and two dozen local participants. Most participants are 
students with a M.Sc. degree, but some are undergraduates and some are post-doctoral scientists.

The academic degree of the participants is less important than the kind of institution they come from: Many of the participants come from a small observatory or a small university department of astronomy. There the teaching is often quite specialized. The students often have learned one subject well, and they may do some research on that subject, but they have only a basic idea about all the rest of astronomy. Therefore, the ISYA usually emphasize a broad range of topics. The lectures at the schools start out quite basic, but the topics are selected so that the lectures will reach the currently exciting research. The topics are chosen by the host institution. Typical topics are solar physics, stellar atmospheres, our Galaxy, cosmology, high-energy astrophysics, observational procedures and data reduction, and the teaching of astronomy.

The IAU pays only for travel of faculty and participants. In fact, for many years UNESCO sponsored the travel costs together with the IAU. The host institution pays for the rooms and meals of faculty and participants, and it provides the meeting facility including a copying machine. Usually the host institution finds some additional sponsors for these costs. In some places, the rooms at a school or institute are available for very little cost, but in some places we have stayed in hotels. On average, in the last few years, the IAU and the host institution have contributed similar amounts of money. But the amount of time and effort provided by the hosts can be very large. For instance, both in China and in Egypt we stayed one week at an isolated observatory. The logistical effort to supply all of us with food at these observatories was quite significant.

\subsection{What do the participants get out of it?}

A much broader perspective on astronomy and on how science works. Many of the students come from an observatory with just one professor of astronomy. These students have learned a narrow part of astronomy, the topic of their professor. Naturally, they take their professor to be the authority on that subject. They have no idea that the same observations might be interpreted differently at some other observatory. They have never heard a scientific argument. Actually, even students from places where there are several astronomy professors have never heard a scientific argument. Therefore, we encourage faculty at the ISYA to present some common topics but with different points of view. We encourage faculty to ask each other questions, to show the relevance of their topics to different fields. At the school in Malaysia, three of us faculty chose a topic on which we could hold a debate. We found to our own surprise that we had three different points of view. That impressed the students!

Practice to ask searching, challenging questions. A student in a small observatory rarely questions a professor, because the student may appear as criticizing the professor. This is especially true in some Asian countries. Students need some practice to ask questions, and they need practice to phrase a question that will elicit a thoughtful and useful answer. At several schools of the last few years, it took at least a week for students to build up the courage to ask questions of the faculty. Once the questions started, and even once students met individually with faculty, it took another week for students and faculty to find a common scientific language and to communicate effectively. That communication with the students is the main reason we ask faculty to stay at the school for at least two weeks. A faculty member who comes for a few days, gives a few lectures, and disappears again is considered by most students as self-serving: this visiting faculty member comes to show that he or she really knows the subject, but demonstrates no apparent concern for the students. 
A new outlook for the students own work. Those students who have done some research are asked to present it briefly. This is often the first time students discuss their topic with a wide audience. They are often shocked that the faculty understand very little of the details they present. In fact, frequently the faculty ask questions during the introduction, because the student does not present the context of the problem. But the students are also often pleased when one of the faculty finds their work interesting, probably in some connection that would not be made at the students home observatory. Quite often the faculty will then suggest other scientific contacts in this subject, leading to international collaborations. I stress again: for this interaction to happen, a faculty member must be at the school long enough to establish a good communication with the students.

Lecture materials. Of course, the participants learn much astronomy and astrophysics. In fact, three weeks of lectures and observing sessions provide much too much material for the students to absorb. Therefore, much of the detailed material is distributed in written form to the participants. When the participants return home, the copied materials often provide a significant increase to the astronomy library. That is why I carefully mentioned the copier machine as an important contribution to the school by the host institution.

Spoken English. Finally, a very important goal of most schools is that the participants learn to talk in English. English is now the international language of science. Indeed, our participants must be able to read English. But most have rarely heard English spoken and most have never spoken English themselves. During the first week of an ISYA, many non-English speaking participants are very quiet. The second week they talk a few sentences. And the third week you cannot stop them talking in English. At the school in China, even the Russians talked to each other in English. In my opinion, learning useful English is the main reason that most schools are three weeks long.

Learning useful English is yet another important reason that faculty should stay at the school as long as possible. It takes much time to establish good scientific communication in spoken English. I know that many participants have stayed in touch for many years, by writing to each other in English. They would not have dared to do this before they attended the school.

\subsection{What does the host institution get out of it?}

Recognition. First, an ISYA may mean official recognition of the importance of astronomy, official recognition from the university and from the government. When the IAU sponsors an event, the word International opens many doors. This practical influence of the IAU may well be worth more to the host institution than the IAUs financial support. In schools such as Indonesia and Malaysia, high government officials have opened the schools. In Nigeria, the school led to the formation of the Department of Physics and Astronomy, the first such department in the developing countries south of the Sahara.

Second, the host institution acquires some international recognition within the astronomical community, because after the school the faculty and participants disperse across some twenty countries.

Start a group of astronomy students. When I first met Bambang Hidayat in Indonesia before the first school there, he was very much scientifically alone at his observatory. Later, I found that this school created a working community of astronomers. Some were working with Bambang, and some were teaching astronomy or working in the space program elsewhere in Indonesia. Similarly, the school in Nigeria led to a great deal of astronomical activity. One of the students from the school in Nigeria has obtained an astronomy doctorate abroad and has now returned as professor at a different Nigerian university. 
Broaden the training of astronomy students and young researchers in the host country. This has probably been the main goal for schools in some of the large countries, like China, India, Argentina, and Brazil. The schools in these countries attracted participants from several universities and research institutions spread all over the country. In many such places, there are already some astronomy students, and there are already physics students interested in astronomy. But the courses and the training available in these places tend to be limited and specialized. The ISYA allows the import of several faculty with broad interests who can energize astronomy throughout the country.

Many schools have attracted participants from neighboring disciplines, especially from physics. Some ISYA have also tried to attract amateur astronomers and interested people in substantially other sciences. This has probably been the least satisfactory aspect of the ISYA. These schools had to start with a rather low academic level. Then many participants gained nothing from the faculty's attempt to advance the lectures to some current research-oriented topics.

Do the ISYA really work? I have surveyed the participants from three schools. I received very good reviews from many foreign participants, and in general from those local participants that really were active in the school. We had the least response from the local students who only came part-time. They gained a few scientific facts, but they missed the discussions, they avoided occasions when they had to talk English, and they did not broaden their outlook on astronomy. I believe, the single most important improvement in the ISYA is to insist that local participants attend full-time. Unfortunately, this is expensive for the local host, because the local students should then be given rooms and meals. Therefore, it is difficult to express this request to the host in a diplomatic manner.

I should acknowledge that the first 18 ISYA were planned by J. Kleczek. M. Gerbaldi has shared with me the planning of the last four ISYA.

\section{Visiting Lecturer Programs (VLP)}

The Visiting Lecturer Programs were instituted to help a university with little astronomy that wanted to enhance its astronomy substantially. Two VLPs were organized, in Peru and in Paraguay. In each case, there was one astronomer, Maria Luisa Aguilar in Peru and Alexis Troche-Boggino in Paraguay. Each worked within the physics department of the national university and was active in training teachers. The goal for the VLP was to establish a small community of astronomers that could be more permanent than one individual.

As a first step, the universities agreed to offer a regular sequence of astronomy courses, as part of the physics curriculum. The first sequence of these courses was to be taught by international visitors. The IAU would pay the travel expenses of the visitors. The host would pay for the local costs. A few students graduating from these courses then were to be sent abroad for further training. After they finish their studies and return home, they would be part of the desired local community of astronomers.

The students in Peru and Paraguay had very little practice in the use of English. Therefore, the VLP courses had to be given in Spanish. We found only very few astronomers both able to speak in Spanish and available for a visit that lasts three months. The astronomers we found could not visit in consecutive semesters. Therefore, only few students were around long enough to attend several astronomy courses. They did not really gain the astronomical background needed to study abroad from these courses. Nevertheless, some of the students from Peru have been able to study in Brazil and are now returning to Peru. Therefore, at least the VLP in Peru seems to have been successful. 
Paraguay has been more connected to Argentina. I think there is still hope for Paraguay. It is important to have patience and perseverence.

Since this is a conference on teaching of astronomy, I want to point out that the astronomers in both of these countries have worked hard to help the teaching of astronomy in the schools of their countries. The teaching of teachers was not really a part of the VLP, but I hope that the existence of the VLP helped these astronomers persevere in their teaching activities.

\section{Teaching for Astronomy Development (TAD)}

The original goal of the VLP was to help countries with little astronomy to develop their astronomy substantially. This goal is still a good one, but the procedures have been made somewhat more flexible under the new program called Teaching for Astronomy Development. We sought applications for TAD from many countries. The IAU Executive Committee has just approved two new programs.

Vietnam. Vietnam has been scientifically isolated for thirty years. We want to help re-establish astronomy in Vietnam. In this, we are joining efforts with astronomers and funds from France and from Japan. The IAU will primarily sponsor a conference to bring current astronomy teachers and physics students up-to-date in several topics of astrophysics.

Central America. We want to help establish astronomy in six cooperating countries of Central America. Primarily the IAU will help fund an annual course in astronomical observations, with participants from all six countries. The course will take place at the new observatory of the National University of Honduras. In this program, we are joining the efforts from the European Commission, which will fund a Central American M.Sc. program in astronomy, somewhat along the lines of our VLP.

It is very important that other international organizations now have similar goals. It is our hope that we can usefully complement the programs supported by the United Nations Office of Outer Space, by the European Commission, by France, Japan and several other international organizations.

\section{Does WWW eliminate scientific isolation?}

Our international schools and the visiting lecturer programs have been aimed at the scientifically isolated astronomy students and astronomers. But technology is changing. Many developing countries can now receive foreign e-mail for perhaps an hour a day. A few countries have real-time international e-mail. That means they can use programs like ftp and telnet. A very few countries, like Honduras, are connected to the world wide web. In Honduras, at least, once again astronomy has been the driving force for the country acquiring new technology. Of course, once you have the web you have access to the data sets from the HST etc. Therefore, in terms of scientific factual information, many astronomers will no longer be isolated.

But the web does not solve all the problems. I believe that many astronomers in these countries will still be physically isolated. They will still need personal contacts to develop the skills of interacting with other astronomers, they will need practice how to question other astronomers data and their interpretation, and they will need active discussions for placing local astronomy in a broader context. To provide these personal contacts has been the aim of the International Schools for Young Astronomers in the past, and I think it will be a perfectly valid goal for future schools. 